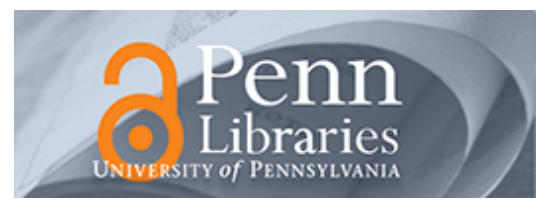

University of Pennsylvania

ScholarlyCommons

Marketing Papers

Wharton Faculty Research

8-2002

\title{
High Stakes Decision Making: Normative, Descriptive and Prescriptive Considerations
}

Howard Kunreuther

University of Pennsylvania

Robert Meyer

University of Pennsylvania

Richard Zeckhauser

Paul Slovic

Barry Schwartz

See next page for additional authors

Follow this and additional works at: https://repository.upenn.edu/marketing_papers

Part of the Marketing Commons

\section{Recommended Citation}

Kunreuther, H., Meyer, R., Zeckhauser, R., Slovic, P., Schwartz, B., Schade, C., Luce, M., Lippman, S., Krantz, D., Kahn, B., \& Hogarth, R. (2002). High Stakes Decision Making: Normative, Descriptive and Prescriptive Considerations. Marketing Letters, 13 (3), 259-268. http://dx.doi.org/10.1023/A:1020287225409

This paper is posted at ScholarlyCommons. https://repository.upenn.edu/marketing_papers/191

For more information, please contact repository@pobox.upenn.edu. 


\title{
High Stakes Decision Making: Normative, Descriptive and Prescriptive Considerations
}

\author{
Abstract \\ This paper reviews the state of the art of research on individual decision-making in high-stakes, low- \\ probability settings. A central theme of the discussion is that optimally resolving high-stakes decisions \\ poses a formidable challenge not only to naïve decision makers, but also to users of more sophisticated \\ tools such as decision analysis.. Such problems are difficult to resolve because precise information about \\ probabilities is not available, and the dynamics of the decision are complex. When faced with such \\ problems, naïve decision-makers fall prey to a wide range of potentially harmful biases, such as not \\ recognizing a high-stakes problem, ignoring the information about probabilities that does exist, and \\ responding to complexity by accepting the status quo. We offer an agenda for future research focusing \\ on how the process and outcomes of high-stakes decision making might be improved.
}

\section{Keywords}

high-stakes decisions, risky decision making, decision heuristics, decision biases, decision making under certainty

\section{Disciplines}

Business | Marketing

\section{Author(s)}

Howard Kunreuther, Robert Meyer, Richard Zeckhauser, Paul Slovic, Barry Schwartz, Christian Schade, Mary Frances Luce, Steven Lippman, David Krantz, Barbara Kahn, and Robin Hogarth 
High Stakes Decision Making:

Normative, Descriptive and Prescriptive Considerations

\author{
Howard Kunreuther* \\ Robert Meyer* \\ Richard Zeckhauser \\ Paul Slovic \\ Barry Schwartz \\ Christian Schade \\ Mary Frances Luce \\ Steven Lippman \\ David Krantz \\ Barbara Kahn \\ Robin Hogarth
}

October 8, 2001

*Session Chairs 


\title{
High Stakes Decision Making: Normative, Descriptive and Prescriptive Considerations
}

\begin{abstract}
$\underline{\text { Abstract }}$
This paper reviews the state of the art of research on individual decision-making in high-stakes, low-probability settings. A central theme of the discussion is that optimally resolving high-stakes decisions poses a formidable challenge not only to naïve decision makers, but also to users of more sophisticated tools such as decision analysis.. Such problems are difficult to resolve because precise information about probabilities is not available, and the dynamics of the decision are complex. When faced with such problems, naïve decision-makers fall prey to a wide range of potentially harmful biases, such as not recognizing a high-stakes problem, ignoring the information about probabilities that does exist, and responding to complexity by accepting the status quo. We offer an agenda for future research focusing on how the process and outcomes of high-stakes decision making might be improved.
\end{abstract}


On September 11, 2001, terrorists attacked the United States. Some 3000 lives were lost, primarily due to the destruction of the World Trade Center towers. The direct damage to property and indirect losses such as business interruption could be as high as as $\$ 40$ billion. The event was unanticipated, indeed hardly imagined, even though terrorists had launched a powerful, albeit mostly unsuccessful attack on the World Trade Center in 1993 and more recently destroyed the U.S. embassies in Dar Es Salaam and Nairobi. Moreover, there was ample information that the U.S. was a prime terrorist target, and that known terrorists were taking pilot training. Assessments of the attack indicate that intelligence failed massively, and that airport security was lax. Why the lack of preparation? As unique as this tragedy may have been, the decision-making errors that led to it were all-too familiar; as a society and individuals we inherently have difficulty contemplating and taking protective actions against low probability, high stakes threats, be they induced by nature or, as on September 11, systematically planned by an opponent.

This paper primarily addresses the way individuals rather than governments make decisions about low probability, high-stakes events. The stakes from these actions are dwarfed by the losses in the terrorist attack. We believe, however, that most of the lessons learned about individual decisions carry over to collective decisions, whether by firms, nonprofits, or various government organizations.

Introduction

The decisions that matter most in life are often those that we are least prepared to make. While our skills may be sophisticated in navigating the net, choosing brands from supermarket shelves, and selecting routes to work, life offers few opportunities to train 
for decisions where the consequences of a poor choice are large and, once made, difficult to reverse. High-stakes decisions, such as what health therapies to adopt and what investment policies to follow, are fraught with high levels of uncertainty and complexity; normative guidance for making them is scarce. What makes these decisions challenging is thus not just the specter of the possible consequences of error, but the awareness of the naiveté with which we are forced to approach them.

How skilled are people at making choices when faced with decisions where there is a low but ambiguous probability of experiencing a high stakes loss? What light do current normative theories of choice shed on how people should decide between alternative options? Can we develop prescriptive guidelines for improving decisionmaking processes in high-stakes settings? These are some of the questions that were the focus of a four-day workshop that sought to establish what we currently know about these issues, and to formulate an agenda for future research. In this paper we review the outcome of these discussions.

\section{The Anatomy of High-Stakes Decisions}

Consider the following decision problem:

You are considering purchasing a flood insurance policy for your home on the banks of the Brown River. You are not too worried about a flood since the Brown is not considered particularly flood prone. On the other hand, you know that a severe flood could cause substantial damage or even destroy your home. Should you purchase the insurance?

This is an example of a class of decision problems that we term high-stakes decisions, defined as problems that share two distinctive properties:

A. The existence of large financial and/or emotional prospective loss outcomes; and

B. The presence of high costs to reversing a decision once it is made. 
Over the past forty years a large literature has evolved that has sought to investigate how individuals make such decisions, focusing on the contrast between how these decisions should be me made by rational agents (such as by applying principles of expected-utility theory) and how they commonly are made. The central conclusion has been disturbing; the presence of potentially catastrophic costs of errors does little to assuage the human tendency to make decisions using simplified heuristics (or rules of thumb) that, at times, yield decisions that significantly depart from those that would be prescribed by normative models. These features include:

\section{- Under- utilization of probability information and failure to differentiate among}

probabilities The rational use of probability information is central to any normative analysis of a high-stakes decision. Yet, several studies show that people either insufficiently utilize probability information when it is made available to them, or ignore it altogether. Huber, Wider, and Huber (1997), for example, report the results of a study where only 22 percent of subjects sought out probability information when evaluating several risky managerial decisions. Even when another group of respondents in this same study was given precise probability information, less than 20 percent mentioned the word probability in their verbal protocols.

Likewise, individuals and firms frequently treat the likelihood of outcomes with high-stakes losses as sufficiently low that they consider them not worth worrying about, thus leading inaction by the decision maker. By assuming that these events will "not happen to me," they are effectively treating their probability as zero, or close to it. In a laboratory experiment on purchasing insurance 
(McClelland, Schulze, and Coursey 1993), or warranties (Schade and Kunreuther 2001), many individuals bid zero for coverage, apparently viewing the probability of a loss as sufficiently small that they were not interested in protecting themselves against it.

Similarly, many residents of communities that are potential sites for nuclear waste facilities have a tendency to dismiss the risk as negligible. (Oberholzer-Gee 1998). Prior to the Bhopal chemical accident in 1984, for example, firms in the industry estimated the chances of such an accident as sufficiently low that that it was not on their radar screen .

- An excessive focus on short time horizons. Many high-stakes decisions are not recognized as such by decision makers because of a tendency to see only on the immediate consequence of actions. Teenagers, for example, often have difficulty seeing the long-term consequences of experimenting with smoking, and governments and firms often fail to appreciate the long-term costs of failing to invest in infrastructures. This tendency toward myopia is one of the most widelydocumented failings of human decision making; as a rule, we have difficulty considering the future consequences of current actions over long time horizons (see, e.g., Meyer and Hutchinson 2000). Hence, we see decision makers fail to invest in measures that make their houses more disaster-resistant (Kunreuther, Onculer and Slovic 1998), under-invest in energy-saving appliances (Hausman 1979), and undervalue the benefits of exploratory medical testing (Luce and Kahn 1999). 
- Excessive attention to affectual cues. Affect and emotions strongly influence decisions involving uncertain outcomes with large consequences (Slovic, et al 2001; Loewenstein et al 2001). Decisions requiring difficult trade-offs between attributes or entailing ambiguity as to what would constitute a "right" answer, often lead individuals to resolve choices by focusing on cues that send the strongest affective signals.

To illustrate, Slovic, et al (2001) report the results of an experiment in which a group of subjects was asked to place a value on new airport safety equipment that would save 150 lives for sure under certain circumstances. Other groups were then asked the same question, with one change: only proportions of 150 lives, ranging from $85 \%$ to $98 \%$, would be saved. Common sense would dictate that saving the 150 lives for sure would be valued most highly. However, subjects who did not see the prospects side-by-side provided higher evaluations for all proportions greater than $90 \%$. Why? The authors suggest that terms like "98\% success rate" carry a strongly positive, commonly held, affective association that inflates responses, an illustration of what they term the affect heuristic.

The affect heuristic may also drive people to undertake protective measures, even if experts estimate the chances of disaster to be extremely low. Such behavior would not arise from risk aversion in the classic sense; i.e., a calculated assessment of the expected utility of mitigation under a concave loss function. Rather, it emerges from a visceral response to the mere existence of risk, with no consideration for probabilities. 
- Distortions under stress. Many high-stakes decisions produce high levels of perceived stress. A large number of empirical studies find that if the stress level is not too high it focuses decision makers on a selective set of cues when evaluating options (e.g., Kahn and Baron 1995; Ben Zur and Breznitz 1981; Kahn and Luce 2001) and leads them to make greater use of simplifying heuristics (e.g., Luce, Bettman, and Payne 1997).

Whether such selective attention depreciates the quality of high-stakes decisions is unclear. It may allow decision makers to make more reliable use of existing salient cues, something that can enhance performance in some settings (see, e.g., Hammond 2000). However, where comprehensive processing is necessary, stress can hamper decisions. For example, Levi and Tetlock (1980) found that the Japanese navy's chief-of-staff's discussions with officials during 1941 became increasingly rhetorical and less integrative as the decision to attack the United States approached, perhaps making the decision increasingly irrevocable.

Over-reliance on social norms. A central feature of most high-stakes decisions is that individuals have little experience dealing with them, and are highly uncertain about how to resolve them — what Hogarth, Michaud and Mery (1980) term procedural uncertainty. In such cases a natural resolution is to adopt the decision strategies used by others, or follow established social norms (e.g., Kahn and Baron 1995; Sunstein 1996). The risk, of course, is that established rules and norms may be misguided, something that will reinforce rather than eliminate biases. 
To illustrate, consider the decision on whether to invest in protection against a natural disaster. Not surprisingly, people who bought flood or earthquake insurance in the 1970s remarked that the most important reason for purchasing coverage was that someone else had done so. However, many of the originally insured had little information on the actual costs of coverage or the risks associated with future disasters, suggesting that these new decisions were, in many cases, perpetuations of earlier errors (Kunreuther et al 1978).

- The tendency to prefer the status quo. What happens when individuals are presented with difficult choices with multiple options and no obvious right answer? A common reaction is to make no decision at all—either by opting for a status quo course of action or, if there is none, walking away from the decision entirely (Samuelson and Zeckhauser 1988; Schwartz et al 2002)—a tendency termed the status-quo bias.

The particular danger for high-stakes decisions is that decision makers must resolve difficult trade-offs, where many courses of action are better than a status quo. When faced with decisions that involve life-and-death trade offs, people frequently remark, "I'd rather not think about it", or relegate the decision to an agent—both potentially dysfunctional responses (Schwartz et al 2002).

- Failures to learn. If individuals could learn well from experience, their limited information about the likelihood and consequence of uncertain events would be less of an obstacle to effective decision making. Unfortunately, there is little empirical basis for such optimism about high-stakes choices. There are little data 
from which to learn, and feedback is commonly sparse and censored.

As an illustration, Meyer and Hutchinson (2001) report evidence that participants in an earthquake simulation tended to over-invest in mitigation that was normatively ineffective but under-invest when it is normatively effective. The reason was misinterpretation of feedback; when mitigation was ineffective, respondents attributed the persistence of damage to the fact that they had not invested enough. By contrast, when it was effective, they attributed the absence of damage to a belief that earthquakes posed limited damage risks!

\section{Can High-Stakes Decisions be Made More Effective?}

The above features of decision making involve limitations in our ability to process information, but their effects are not necessarily destructive. In many situations, heuristics and biases are optimal adaptations to routine problems (e.g., Payne, Bettman, and Johnson 1988). For example, for most common forecasting tasks a recency bias can be beneficial. If we see an acquaintance in a bad mood at 1PM, he is likely to still feel sour an hour later. The best single predictor of the weather tomorrow is, in fact, the weather today. Such simple extrapolations may catch us without an umbrella when it rains, but the costs are likely to be minimal.

In contrast, in many high-stakes decisions this heuristic is decidedly inappropriate, and the cost of misapplication can be huge. For example, as memories of a flood recede, many individuals construct houses on the flood plain believing that it will not happen to me. In fact, it is not uncommon to hear residents in these areas say: "We just had our 100 year flood so we won't have another one for a while." Improving highstakes decisions will not simply be a matter of stamping out decision makers' biases. 
Rather, they must learn to intuitively recognize when biases may actually help decision making, and when they are likely to be harmful. Such discrimination would be challenging even to a trained decision analyst.

With this caveat in mind, we can identify two ways for achieving this goal:

1. Teach prescriptive heuristics to individuals Although standard models of rational decision making-- incorporating Bayesian analysis and Von NeumannMorgenstern utility functions -- will not resolve many high-stakes decisions, they can help individuals improve the choice process by think about the chances of certain events occurring and the relevant types of tradeoffs that should be considered. Statistical training has been shown to have a strong effect on inductive reasoning on performance in the short-run (Fong, Krantz, \& Nisbett 1986), and may help improve high-stakes decision making.

As we have noted above, however, in many cases the core problem is not that decision makers are unaware of the need to consider relative probabilities and consequences, but rather are limited in their ability to process this information in an optimal manner. Remedying this calls for the development of prescriptive heuristics, or rules of thumb that enhance normative processing in light of natural processing limitations. Consider, for example, the difficulty that individuals have in evaluating low-probability risks. People are likely to be more sensitive to the probability dimension if risks are presented in a concrete form, so the decision making has a clear context for evaluating a given likelihood (Hsee 1996). An individual with little understanding of a probability of 0.000001 might better interpret it when it is expressed in relation to a familiar probabilistic event, such 
as the risk of an automobile accident, or by translating probabilities into frequencies (e,g,, Slovic, Monahan, and MacGregor 2000)..

Adjusting the time frame also enhance the accuracy of risk perceptions. For example, if a firm is considering earthquake protection over the 25 -year life of a plant, managers are far more likely to take the risk seriously if they are told the chance of an earthquake is 1 in 4 during the entire period rather than 1 in 100 in any given year (Weinstein, Kolb, and Goldstein 1996). Similarly, people are more willing to wear seatbelts if they are told they have a one third chance of a serious accident over a 50-year driving lifetime of driving rather than a 0.00001 chance each trip (Slovic, Fischhoff, and Lichtenstein (1978).

Similar framing approaches might also help address other decisionmaking biases, such the reluctance to take costly actions now whose benefits exist only in the future - such as convincing teenagers not to start smoking. EU-type arguments that focus on the conditional probabilities of incurring lung cancer and heart disease later in life are not promising. But teenagers may be swayed by salient visual demonstrations of the immediate consequences of smoking on the lungs, esophagus, teeth and other parts of the body—demonstrations that hold high affective content, and hence get heavily weighted.

Finally, there also evidence that decision making can be improved by encouraging decision makers to see events through alternative frames, such as gains versus losses and changes in the status-quo. In medical decisions there may be major differences between how a patient views a costly therapy that is presented in terms of extending life or precluding a shortening of life. Likewise, 
preferences for insurance policies can be dramatically altered by changing what constitutes the default coverage (Johnson, et al 1993).

2. Develop Financial Incentives Improved training and finding more effective means to present information are, of course, only partial remedies for enhancing the quality of high-stakes decisions. For example, making the long-term consequences of actions more salient through affect-laden communications may help moderate the myopia bias it will never eliminate it entirely, particularly when the bias is exacerbated by real constraints such as limited budgets for investing in certain activities. Such situations often argue for overt intervention by materially altering the cost structure of decision problems. For example, one can make opportunity costs salient by providing explicit monetary incentives for undertaking protective actions, or avoiding harmful behaviors. While a homeowner in a marginally hurricane-prone area may have difficulty envisioning the long-term benefits of spending $\$ 10,000$ for storm shutters, this can be made concrete by offering her long-term insurance discounts for undertaking the improvement, and providing a loan (perhaps attached to the mortgage) that speads the costs of the measure over a long period.

Up until now, we have overlooked issues in decision-making that arise when biases are the source of risk rather than simply an obstacle to its resolution. Firms pollute, homebuilders cut corners on construction, and governments fail to curb global warming because the consequences seem both distant and, often, more likely to be incurred by others rather than themselves. The distortions of myopia are powerful, and its effects potentially devastating. In such instances legislative 
intervention may be called for to either force long-term thinking when it is neglected or to offer explicit incentives for doing so. Examples are numerous, such as in building codes and safety standards. While many industry groups lobby against such restrictions (arguing that they are costly and unneeded), the fact remains that citizens will inherently be at higher risk without them.

\section{Conclusions and Agenda}

The goals of better understanding the psychology of high-stakes decision making and improving the quality of decision outcomes are closely intertwined. Once we understand the biases that limit intuitive solutions, we can understand where normative theory holds its greatest benefits. Likewise, the best prescriptive aids for decision making will likely be those that are congruent with the processes that arise naturally in problem-solving.

With this in mind, we identified five critical areas for future research that reflect this intertwining of normative and descriptive research agendas:

1. Develop a better normative model of choice for high-stakes decision making that incorporates psychological considerations such as affect, hyperbolic discounting, status quo bias, non-Bayesian learning, framing, and non-linear treatment of probabilities. The traditional arguments for ignoring such effects are compelling in repeated-decision contexts, such as stock investing. However, they apply less cogently to one-time only decisions, such as critical medical decisions. A generalized model would 
not recommend specific actions, but rather help a decision maker explore alternatives in a model that realistically captures their behavior.

2. Provide better theories of high-stakes decisions at the group, organizational and societal levels. Most understanding about high-stakes decision-making comes from the study of individuals. We know surprisingly little about how such decisions are resolved by groups, firms, and governments, and the role that social influences play on individual decisions (Zeckhauser and Viscusi 1990).

3. Generate more systematic evidence on the efficacy and limitations of training. Can people be trained to think like statistical decision makers when making high-stakes decisions? What are the most effective heuristic training devices for improving the quality of these decisions? Does training in de-biasing generalize over time and context? Our current knowledge about these fundamental questions is largely anecdotal.

\section{Improve tools for representing ambiguous probabilities and uncertain outcome} spaces. Earlier we noted that a major challenge facing attempts to apply standard normative theory to high-stakes decisions is that our knowledge of the outcome space is almost always incomplete; we know neither what the full set of consequences might be nor the probabilities that should be associated with these consequences. We need tools for representing ambiguous decision problems — possibly drawing from descriptive research on how individuals intuitively deal with this type of uncertainty.

5. Conduct empirical tests of how financial incentives play a role in dealing with high stake decisions. Financial incentives can naturally lead 
individuals to better long-run decision outcomes — such as explicitly rewarding long-term investing. The design of these incentives requires a better understanding of their goals as well as the types of heuristics they use in making decisions. More controlled experiments and pilot studies need to be undertaken to determine how well alternative incentive programs would perform.

As a final note, just as most of our decision making skills focus on solving recurring, relatively low-stakes tasks, so too has most of the academic literature in applied choice modeling. We know an enormous amount about how consumers choose modes of transit to commute to work, select among brands of coffee, and, more recently, select web sites to visit. By comparison we know much less about how individuals solve the complex problems that are often far more critical to both themselves and to society-how we make fundamental decisions about their health, or choose collectively how much to invest in precautions against global terrorism. Such decisions are not sufficiently captured by the tools of standard applied choice modeling, where choice primarily involves a static, dispassionate, comparison of options. The study of the distinctive features of high-stakes decision making is just beginning. It rationally merits the interests of an expanding set of theoretical and applied researchers. 


\section{References}

Ben Zur, H., and S.J. Breznitz (1981), “The Effect of Time Pressure on Risky Choice Behavior", Acta Psychologica, 47, 89-104

Fong, Geoffrey T; Krantz, David H; Nisbett, Richard E. (1986) "The Effects of Statistical Training on Thinking About Everyday Problems". Cognitive Psychology, 18(3), 253-292.

Hammond, K (2000), Judgments Under Stress, New York: Oxford University Press.

Hausman, J. (1979), "Individual Discount Rtaes and the Purchase and Utilization of Energy-Saving Durables", Bell Journal of Economics, 10: 33-45.

Hogarth, R. Michaud, C. and Mery, J-L (1980) "Decision Behavior in Urban Development: A Methodological Approach and Substantive Considerations" Acta Psychologica 45: 95-117.

Hsee, C. (1996) "The Evaluability Hypothesis: An Explanation of Preference Reversals Between Joint and Separate Evaluations of Alternatives" Organizational Behavior and Human Decision Processes 46:247-257.

Huber, O., Wider, R. and Huber, O. (1997) "Active Information Search and Complete Information Presentation in Naturalistic Risky Decision Tasks" Acta Psychologica 95:15-29.

Johnson, E., Hershey, J., Meszaros, J. and Kunreuther, H. ( 1993) "Framing, Probability Distortions, and Insurance Decisions" Journal of Risk and Uncertainty 7: 35-51.

Kahn, B. E. and J. Baron (1995), "An Exploratory Study of Choice Rules Favored for High Stakes Decisions," Journal of Consumer Psychology, Vol. 4 (4), 305-328.

Kahn, B. E. and M. F. Luce (2001), "Modeling High Stakes Consumer Decisions in Repeated Contexts: The Problem of Mammography Adherence Following False Alarm Test Results," The Wharton School Marketing Department Working Paper Series.

Kunreuther, H., Novemsky, N. and Kahneman, D. (2001) “Making Low Probabilities Useful” Journal of Risk and Uncertainty

Kunreuther, H., Onculer, A. and Slovic P. (1998) "Time Insensitivity for Protective Measures", Journal of Risk and Uncertainty, 16: 279-299.

Kunreuther, H. (et al. (1978) Disaster Insurance Protection: Public Policy Lessons (New York: Wiley). 
Levi, A., and P. E. Tetlock (1980), “A Cognitive Analysis of Japan's 1941 Decision for War", Journal of Conflict Resolution, 24, 195-211

Loewenstein, G., Weber, E, Hsee, C. and Welch, E. (2001) "Risk as Feelings" Psychological Bulletin 127: 267-86.

Luce, M.F., J.R. Bettman and J.W. Payne (1997), "Choice Processing in Emotionally Difficult Decisions", Journal of Experimental Psychology: Learning, Memory, and Cognition, 23, 384-405.

Luce, M.F. and Kahn, B. (1999) "Avoidance or Vigilance? The Psychology of FalsePositive Test Results” Journal of Consumer Research 26: 242-59.

McClelland, G. and Schulze, W. and Coursey, D. (1993) "Insurance for Low-Probability Hazards: A Bimodal Response to Unlikely Events" Journal of Risk and Uncertainty 7:95-116.

Meyer, R. and Hutchinson, W. (2001) "Bumbling Geniuses: The Power of Everyday Reasoning in Multistage Decision Making" in Hoch, S.and Kunreuther, H. with Gunther, R. Wharton on Making Decisions New York: John Wiley.

Oberholzer-Gee, F. (1998) "Learning to Bear the Unbearable: Towards and Explanation of Risk Ignorance,“ mimeo, Wharton School, University of Pennsylvania.

Payne, J.W., J.R. Bettman, and E.J. Johnson (1988), “Adaptive Strategy selection in Decision Making". Journal of Experimental Psychology: Learning, Memory, and Cognition, 14. 534-552

Samuelson, W. and Zeckhauser, R. (1988) "Status Quo Bias in Decision Making" Journal of Risk and Uncertainty, 1:7-59.

Schade, C. and Kunreuther, H. (2001) "Worry and the Illusion of Safety" Working Paper, Wharton Risk Management and Decision Processes Center University of Pennsylvania, Philadelphia, PA.

Schwartz, B., Ward, A., Monterosso, J., Lyubomirsky, S., White, K., \& Lehman, D.R. (2002). Maximizing Versus Satisficing: Happiness Is a Matter of Choice. Manuscript under review.

Slovic, P., M. Finucane, E. Peters, and D. MacGregor (2001), "The Affect Heuristic", in T. Gilovich, D. Griffin, and D. Kahneman (Eds.), Intuitive Judgment: Heuristics and Biases, Cambridge University Press, in press.

Slovic, P., Fischhoff, B., and Lichtenstein, S. (1978) “Accident Probabilities and Seat 
Belt Usage: A Psychological Perspective" Accident Analysis and Prevention 10: 281:285.

Slovic, P., Monahan, J., \& MacGregor, D. G. (2000) "Violence risk assessment and risk Communication: The effects of using actual cases, providing instruction, and employing probability versus frequency formats" Law and Human Behavior

Sunstein, C. (1996) "Social Norms and Social Roles," Columbia Law Review 96:90368.

Weinstein, N., Kolb, K., and Goldstein, B. (1996) "Using Time intervals Between Expected Events to Communicate Risk Magnitudes" Risk Analysis 16:305-308. Weinstein, N. ed. (1987) Taking Care: Understanding and Encouraging SelfProtective Behavior Cambridge: Cambridge University Press.

Zeckhauser, Richard J. and Viscusi, W. Kip (1990) "Risk Within Reason," Science 248:559-64. 